\title{
Double-blind trial of naproxen and phenylbutazone in ankylosing spondylitis
}

\author{
F. VAN GERWEN, J. K. VAN DER KORST, AND F. W. J. GRIBNAU
}

From the Division of Rheumatology, Department of Medicine, University of Nijmegen, The Netherlands

SUMMARY In a double-blind double-placebo crossover study naproxen (500-750 mg daily) was found to be equivalent to phenylbutazone ( $400-600 \mathrm{mg}$ daily) in the control of disease activity in 20 patients suffering from ankylosing spondylitis during a two times 5-week trial period. No serious side effects were observed during the trial period. Gastric complaints occurred twice as often under phenylbutazone as under naproxen.

Naproxen has been claimed to be a potent analgesic and anti-inflammatory drug with a relatively low incidence of side effects (Roszkowski et al., 1971; Hill et al., 1974; Huskisson et al., 1976). A few preliminary studies have shown a beneficial effect in ankylosing spondylitis (Hill and Hill, 1975; Peter and Veress, 1975). To our knowledge, naproxen has not been compared with phenylbutazone, which is considered the main therapy in this disease. We therefore undertook a double-blind double-placebo crossover study to assess the efficacy and safety of naproxen against phenylbutazone in active ankylosing spondylitis.

\section{Patients and methods}

Of 160 outpatients with definite ankylosing spondylitis already under treatment, only 22 fulfilled the admission criteria of (1) definite ankylosing spondylitis attested by radiographic evidence of bilateral sacroiliitis; (2) age 18 to 65 inclusive; (3) clear evidence of active spondylitis (when not treated with anti-inflammatory or analgesic drugs); with at least 2 of the 5 signs of disease progress: (a) nocturnal pain with morning predominance and/or morning stiffness; (b) pain and stiffness in low back, or dorsolumbar junction or in either or both buttocks of over 3 months' duration and not relieved by rest; (c) pain and stiffness in thoracic region, of over 3 months' duration; (d) limitation of chest expansion ( $<5$ but $>2 \mathrm{~cm}$ ); (e) limitation in spinal anterior and lateral flexion and in spinal extension; (4) ESR $>20 \mathrm{~mm}$ in the first hour.

Accepted for publication July 8, 1977

Correspondence to Professor J. K. van der Korst, Amsterdam Centre for Rheumatic Diseases, Dr Jan van Breemenstraat, Amsterdam, The Netherlands
Patients with one of the following criteria were excluded: (1) women of child-bearing age; (2) patients with secondary ankylosing spondylitis, such as Behcet's or Reiter's disease; (3) total immobility of the spine and of the costovertebral joints; (4) patients on anticoagulants, hypoglycaemic agents, sulphonamides or other drugs highly bound to plasma proteins; (5) a history of definite peptic ulcer or gastrointestinal bleeding (within the previous 2 years), or ulcerative colitis or regional enteritis at any time; or any significant gastrointestinal disease likely to interfere with drug absorption; (6) a history of hypersensitivity to phenylbutazone or to other nonsteroidal anti-inflammatory drugs, (7) a history of hepatic disease or liver function tests $25 \%$ or more above the normal laboratory values and a history of renal disease shown by blood urea nitrogen (BUN) and creatinine $30 \%$ above normal values; (8) those with conditions such as cerebral vascular accident, existing cardiac failure, coronary occlusion within the previous 6 months, active tuberculosis, metabolic bone disease, haematopoietic disorder, malignant disease, depression, or other mental disorders, likely to interfere with the course of or assessment of disease progress.

Patients were assigned randomly to either of two sequences. In sequence A patients were given for the first 5 weeks two tablets of naproxen $250 \mathrm{mg}$ each daily plus 4 placebo tablets mimicking phenylbutazone; for the following 5 weeks they were given twice daily 2 tablets phenylbutazone of $100 \mathrm{mg}$ each plus one placebo tablet identical to the naproxen tablets taken previously. Sequence B was similar but during the first 5-week period the patients took phenylbutazone as the active drug and naproxen was taken in the second 5-week period. No "washout' period was included either before the trial or at 
the time of crossover. Patients were switched immediately from their previous drug therapy to both trial medications.

The patients were interviewed and examined at the start of the trial and weekly thereafter. At each visit their evaluation of spinal pain (cervical, thoracic, and lumbar/sacroiliac) and night pain, using a scale from 0 to 4 , was recorded as well as duration of morning stiffness and of immobility stiffness (Hill and Hill, 1975) in minutes, and onset of fatigue after rising in the morning in hours. The investigator each week evaluated spinal pain in the same three areas (scale 0-4), and overall disease activity (scale 0-3). Chest expansion, finger to floor and occiput to wall distances in $\mathrm{cm}$, and the modified Schober test (van Adrichem and van der Korst, 1973) were measured each week and in all instances the best of two measurements was recorded. Erythrocyte sedimentation rate was assessed weekly.

At weeks 0, 3, 5, 8, and 10 measurements of haemoglobin, haematocrit, leucocyte and platelet counts, transaminases, alkaline phosphatase, BUN, and creatinine were made, as well as urinalysis including protein, glucose, and sediment. Side effects, blood pressure, pulse rate, and body weight were recorded weekly. At the start of the trial, during the crossover (between weeks 5 and 6), and at the end of the trial visual acuity and slit lamp examination and fundoscopy were performed by an ophthalmologist. At the end of each 5-week period the patients and the investigator gave their opinion of the overall response to the treatment, according to a scale ranging from 5 (none) to 1 (excellent).

Before the trial a pharmacist prepared bottles labelled with the patient's number and the number of the week. Each week the patient received two bottles, one containing naproxen or its placebo and the other phenylbutazone or its placebo. Each bottle contained enough tablets for a total daily dosage of naproxen to $750 \mathrm{mg}$ and of phenylbutazone to $600 \mathrm{mg}$. At the next visit the patient returned the bottle and the remaining tablets were counted.

\section{Results}

Of the 22 patients entered in the study, one dropped out during the first period because of epigastric intolerance. All other patients completed both phases of the study, but to equalise the two groups, the data of one other patient were disregarded in the results. The two groups of 10 patients were comparable for sex, age, weight, height, functional class, duration of disease, and response to previous treatment (Table 1). In both groups 3 patients had been receiving indomethacin and 7 phenylbutazone during the 6 months immediately preceding the trial. There were no significant differences in the dosage of both drugs.

During the trial most of the patients experienced less pain and stiffness, although they had been on 'full' treatment up to that time. However, n significant differences were found between the tw drugs with regard to the patient's evaluation $f$ spinal pain, nocturnal pain, morning stiffnes? immobility stiffness, and onset of fatigue (Table $2 \frac{5}{6}$ The proportion of patients with nocturnal pain was equal after naproxen and phenylbutazone.

The overall response to naproxen and phenyts butazone was assessed as equivalent (at the $5 \%$ level) by the patients. In 9 the dosage was increased because of increasing complaints of pain and/8 stiffness, three times during the first period and sE times during the second period. 4 patients were ơp phenylbutazone and 5 on naproxen when increased dosage was necessary to continue the trial.

Table 1 Clinical details of patients on entry to a double-blind crossover study of naproxen and phenylbutazone in ankylosing spondylitis

\begin{tabular}{|c|c|c|}
\hline & $\begin{array}{l}\text { Sequence A } \\
\text { (naproxen- } \\
\text { phenylbutazone) }\end{array}$ & $\begin{array}{l}\text { Sequence B } \\
\text { (phenylbutazone } \\
\text { naproxen) }\end{array}$ \\
\hline \multicolumn{3}{|l|}{ Age (yrs) } \\
\hline Mean & $36 \cdot 5$ & $34 \cdot 5$ \\
\hline Range & $21-51$ & $24-54$ \\
\hline \multicolumn{3}{|l|}{ Weight (kg) } \\
\hline Mean & $71 \cdot 1$ & $76 \cdot 9$ \\
\hline Range & $59 \cdot 3-82 \cdot 6$ & $59 \cdot 0-95.0$ \\
\hline \multicolumn{3}{|l|}{ Height $(\mathrm{cm})$} \\
\hline Mean & $173 \cdot 8$ & $176 \cdot 5$ \\
\hline Range & $161 \cdot 5-184 \cdot 6$ & $159 \cdot 3-184 \cdot 7$ \\
\hline \multicolumn{3}{|l|}{ Functional class } \\
\hline Mean & $1 \cdot 6$ & $2 \cdot 0$ \\
\hline Range & $1-3$ & $1-3$ \\
\hline \multicolumn{3}{|c|}{ Disease duration (yrs) } \\
\hline Mean & $8 \cdot 5$ & $10 \cdot 5$ \\
\hline Range & $3-16$ & $3-15$ \\
\hline \multicolumn{3}{|c|}{$\begin{array}{l}\text { Response to previous treatment } \\
\text { (score) }\end{array}$} \\
\hline Mean & $2 \cdot 1$ & $1 \cdot 6$ \\
\hline Range & $1-5$ & $1-2$ \\
\hline
\end{tabular}

Table 2 Patients' evaluation of naproxen and phenylbutazone (mean $\pm 2 S D$ )

\begin{tabular}{|c|c|c|c|}
\hline \multirow[t]{2}{*}{ Parameters } & \multirow[t]{2}{*}{ Before } & \multicolumn{2}{|c|}{ After 5 weeks' treatment } \\
\hline & & Naproxen & Phenylbutaz \\
\hline $\begin{array}{l}\text { Spinal pain } \\
\text { (score) } \\
\text { Morning stiffness } \\
\text { (min) } \\
\text { Immobility stiffness } \\
\text { (score) } \\
\text { Fatigue onset (h) } \\
\text { Nocturnal pain } \\
\text { (no. patients) } \\
\text { Overall response } \\
\text { (score) }\end{array}$ & $\begin{array}{l}2 \cdot 72 \pm 1 \cdot 67 \\
50 \cdot 77 \pm 51 \cdot 55 \\
3 \cdot 31 \pm 1 \cdot 31 \\
8 \cdot 04 \pm 2 \cdot 71 \\
12\end{array}$ & $\begin{array}{l}2 \cdot 28 \pm 1 \cdot 36 \\
38 \cdot 08 \pm 24 \cdot 54 \\
3 \cdot 75 \pm 1 \cdot 06 \\
7 \cdot 69 \pm 2 \cdot 87 \\
4 \\
3 \cdot 2 \pm 0.9\end{array}$ & $\begin{array}{l}2 \cdot 72 \pm 2 \cdot 11 \\
37 \cdot 69 \pm 26 \cdot( \\
3 \cdot 63 \pm 1 \cdot 3 \\
7 \cdot 38 \pm 2 \cdot 5 \\
5 \\
3 \cdot 1 \pm 0.9\end{array}$ \\
\hline
\end{tabular}


With regard to the physician's assessment (Table 3), only spinal pain showed a slight improvement during the study. No changes were observed in the objective measurements, i.e. spinal mobility and chest expansion. Direct comparison of both drugs by Student's $t$ test (adapted for crossover studies) showed no significant differences in any of the variables tested, although a slight trend in favour of naproxen was found for spinal pain, ESR, and disease activity. The physician's assessment of the overall response to both drugs proved to be equivalent.

During the trial all laboratory parameters remained within normal limits with the exception of BUN, a slight rise occurring in 6 patients, three during naproxen treatment and three others during phenylbutazone treatment. In all instances BUN values returned to normal at the next assessment, with no alteration in treatment. No concurrent increase in creatinine levels nor proteinuria were found. Laboratory investigations before the study and after each drug period were all within normal limits (Table 4). No differences were found between the drugs for serum creatinine levels or platelet and WBC counts.

Table 3 Physician's evaluation of naproxen and phenylbutazone (mean $\pm 2 S D$ )

\begin{tabular}{|c|c|c|c|}
\hline \multirow[t]{2}{*}{ Parameter } & \multirow[t]{2}{*}{ Before } & \multicolumn{2}{|c|}{ After 5 weeks' treatment } \\
\hline & & Naproxen & Phenylbutazone \\
\hline \multicolumn{4}{|l|}{$\begin{array}{l}\text { Spinal pain } \\
\text { (score) }\end{array}$} \\
\hline $\begin{array}{l}\text { Chest expansion } \\
\text { (cm) }\end{array}$ & $3 \cdot 82 \pm 1 \cdot 54$ & $4 \cdot 05 \pm 2 \cdot 17$ & $4 \cdot 08 \pm 2 \cdot 17$ \\
\hline $\begin{array}{l}\text { Finger-floor } \\
\text { distance (cm) } \\
\text { Ccciput-wall }\end{array}$ & $18 \cdot 93 \pm 14 \cdot 40$ & $20 \cdot 78 \pm 13 \cdot 96$ & $20 \cdot 83 \pm 13 \cdot 97$ \\
\hline $\begin{array}{l}\text { distance }(\mathrm{cm}) \\
\text { Schober test }\end{array}$ & $8 \cdot 26 \pm 4 \cdot 23$ & $8 \cdot 45 \pm 4 \cdot 36$ & $8 \cdot 68 \pm 4 \cdot 91$ \\
\hline $\begin{array}{l}(\mathrm{cm}) \\
\operatorname{ESR}(\mathrm{mm} / 1 \mathrm{st} \mathrm{h})\end{array}$ & $\begin{array}{r}3 \cdot 76 \pm 2 \cdot 57 \\
34 \cdot 0 \pm 19 \cdot 33\end{array}$ & $\begin{array}{r}3 \cdot 69 \pm 2 \cdot 33 \\
26 \cdot 39 \pm 10 \cdot 44\end{array}$ & $\begin{array}{r}3 \cdot 69 \pm 2 \cdot 44 \\
30 \cdot 17 \pm 19 \cdot 37\end{array}$ \\
\hline Disease activity & $1 \cdot 17 \pm 0.71$ & $0.83 \pm 0.79$ & $1.06 \pm 0.80$ \\
\hline \multicolumn{3}{|c|}{ Therapy response } & $4 \cdot 00 \pm 1 \cdot 71$ \\
\hline
\end{tabular}

However, phenylbutazone was associated with significantly lower haemoglobin and haematocrit values and with higher BUN levels. On the other hand, transaminase levels were significantly higher after naproxen. All these changes, though statistically significant, were not considered relevant since they remained within the normal range.

No objective clinical side effects were observed during the trial. Gastric pain was by far the most frequent side effect, occurring more frequently during phenylbutazone therapy and accounting for 9 of the 15 recorded side effects (Table 5). Only one patient had to be withdrawn from the study because of gastric complaints during phenylbutazone treatment. Ophthalmological investigation, including slit lamp examination, at the end of both trial periods was normal.

\section{Discussion}

For this short-term trial the double-blind doubleplacebo crossover design was chosen to assess the value of naproxen in the treatment of ankylosing spondylitis and to compare it with phenylbutazone. The crossover method-with all patients being given each drug in turn-allows the use of a relatively small number of patients. The double-placebo technique reduced the risks of either the investigator or the patients guessing which active drug was being

Table 5 Side effects of naproxen and phenylbutazone during study

\begin{tabular}{lll}
\hline & Naproxen & Phenylbutazone \\
\hline $\begin{array}{l}\text { Gastric pain } \\
\text { Diarrhoea }\end{array}$ & 3 & 6 \\
$\begin{array}{l}\text { Headache } \\
\text { Drowsiness } \\
\text { Vertigo }\end{array}$ & 1 & - \\
$\begin{array}{l}\text { Dizziness + dryness } \\
\text { of mouth }\end{array}$ & $1-$ & $\frac{1}{1}$ \\
\begin{tabular}{l} 
Total \\
\hline
\end{tabular} & 1 & 1 \\
\hline
\end{tabular}

Table 4 Laboratory investigations during study

\begin{tabular}{|c|c|c|c|c|}
\hline \multirow[t]{2}{*}{ Parameters } & \multirow[t]{2}{*}{ Before } & \multicolumn{2}{|c|}{ After 5 weeks' treatment } & \multirow[b]{2}{*}{$P$} \\
\hline & & Naproxen & Phenylbutazone & \\
\hline $\begin{array}{l}\text { Haemoglobin }(\mathrm{mmol} / 1) \\
\text { Haematocrit }(1 / 1) \\
\text { WBC }\left(\times 10^{9} / 1\right) \\
\text { Platelet count }\left(\times 10^{9} / 1\right) \\
\text { Alkaline phosphatase }(\mathrm{U} / 1) \\
\text { SGOT }(\mathrm{U} / 1) \\
\text { SGPT }(\mathrm{U} / \mathrm{l}) \\
\text { BUN }(\mathrm{mmol} / \mathrm{l}) \\
\text { Creatinine }(\mu \mathrm{mol} / \mathrm{l})\end{array}$ & $\begin{array}{r}9.30 \pm 0.78 \\
0.44 \pm 0.04 \\
6 \cdot 74 \pm 1.48 \\
271 \cdot 30 \pm 78 \cdot 14 \\
101.65 \pm 21 \cdot 53 \\
4.85 \pm 1.69 \\
6 \cdot 50 \pm 3 \cdot 27 \\
5.77 \pm 1.53 \\
82.25 \pm 8 \cdot 19\end{array}$ & $\begin{array}{r}9.00 \pm 0.68 \\
0.43 \pm 0.03 \\
7.41 \pm 1.26 \\
252.60 \pm 61.99 \\
90.70 \pm 24.08 \\
5.25 \pm 1.12 \\
7.35 \pm 3.50 \\
6.26 \pm 1.60 \\
84.00 \pm 10.35\end{array}$ & $\begin{array}{r}8 \cdot 70 \pm 0.54 \\
0.42 \pm 0.03 \\
7 \cdot 27 \pm 1.42 \\
268 \cdot 35 \pm 77.03 \\
97.20 \pm 22.56 \\
4.30 \pm 1 \cdot 13 \\
5.85 \pm 2.37 \\
7.05 \pm 1.78 \\
83.15 \pm 10.65\end{array}$ & $\begin{array}{l}<0.01 \\
<0.05 \\
\text { NS } \\
<0.10 \\
<0.06 \\
<0.01 \\
<0.005 \\
<0.005 \\
\text { NS }\end{array}$ \\
\hline
\end{tabular}

Conversion: SI to traditional units-BUN (blood urea nitrogen): $1 \mathrm{mmol} / 1 \approx 2.8 \mathrm{mg} / 100 \mathrm{ml}$. Creatinine: $1 \mu \mathrm{mol} / 1 \approx 0.113 \mathrm{mg} / 100 \mathrm{ml}$. 
taken and therefore assured as much as possible the maintenance of the double-blindness of the study.

Judging from the rheumatology textbooks there seems to be general agreement that phenylbutazone is the most effective drug in the control of the symptoms of ankylosing spondylitis, although its application is hampered by the risks of severe side effects. The results from our study indicate that the effects of naproxen are equivalent to phenylbutazone, based on both the patient's and the physician's evaluation. Little or no differences were found between the values obtained after the trial periods compared to the baseline values, probably because there was no 'wash-out' period before the trial. In earlier studies about $25 \%$ of patients with active ankylosing spondylitis were unable to complete a period of 5 days without a major anti-inflammatory drug. Because the mean half-life of naproxen in man is 13 hours (Segre, 1975) and phenylbutazone 48 to 72 hours (von Rechenberg, 1962), the length of the trial periods, i.e. 35 days each, was thought sufficient to eliminate completely the possible carry-over effects of preceding treatment.

In contrast with phenylbutazone, few serious side effects of naproxen have been reported. In our study it caused fewer gastric complaints than phenylbutazone. Otherwise, no significant differences between the two drugs with regard to clinical tolerance were found. No consistent abnormal findings were observed among the laboratory parameters, except for transient increase of BUN values occurring with both drugs and in the absence of any other sign of kidney impairment.

Therefore, naproxen seems to be a useful alternative drug to phenylbutazone in the treatment of ankylosing spondylitis, at least on a short-term basis. Recently it has been claimed that long-term treatment with phenylbutazone might delay the ossification of the lumbar discs in ankylosing spondylitis (Boersma, 1976). A long-term comparative study of naproxen and phenylbutazone seems to be wanting.
Naproxen and phenylbutazone tablets, and placeb $\frac{0}{\widetilde{\sigma}}$ tablets were provided by Sarva-Nederland, The Hague, and by Ciba-Geigy, Arnhem, respectively We thank Dr J. Polderman, Brussels, for statistic analysis; Dr F. Lion and Dr A. Pinckers, Dept. of Ophthalmology, University of Nijmegen, for ophthaff mological investigations; and $\mathrm{Mr}$ Kho Han Ya@ pharmacist, Nijmegen, for randomisation and bottling of the tablets.

\section{References}

Adrichem, J. A. M. van, and Korst, J. K. van der (1973 Assessment of the flexibility of the lumbar spine. A pilo study in children and adolescents. Scandinavian Journal of Rheumatology, 2, 87-91.

Boersma, J. W. (1976). Retardation of ossification of the lumbar vertebral column in ankylosing spondylitis bob means of phenylbutazone. Scandinavian Journal of Rheumatology, 5, 60-64.

Hill, H. F. H., and Hill, A. G. S. (1975). Ankylosing spondylitis: open long-term and double-blind crossover studies with naproxen. Journal of Clinical Pharmacology, 15 355-362.

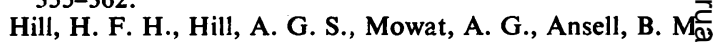
Mathews, J. A., Seifert, M. H., Gumpel, J. M., ane Christie, G. A. (1974). Naproxen. A new non-hurmonal anti-inflammatory agent. Studies in rheumatoid arthrixis Annals of the Rheumatic Diseases, 33, 12-19.

Huskisson, E. C., Woolf, D. L., Balme, W. H., Scott and Franklyn, S. (1976). Four new anti-inflamma面的 drugs: responses and variations. British Medical Journa 1048-1049.

Peter, E., and Veress, M. (1975). Wirkungsvergleich vom Naproxen und Indometacin im Doppelblindversuch beif Nachmitternachtsschmerz von $M$. Bechterew-Krankeø Arzneimittel Forschung, 25, 324-325.

Rechenberg, H. K. von (1962). Phenylbutazone, pp. 8-1 Arnold, London.

Roszkowksi, A. P., Rooks, W. H., Tomolonis, A. J., an Miller, L. M. (1971). Anti-inflammatory and analgesfe properties of d-2-(6'-methoxy-2'-naphtyl-) proprionic acig (naproxen). Journal of Pharmacology and Experiment. Therapeutics, 179, 114-123.

Segre, E. J. (1975). Naproxen metabolism in man. Journ of Clinical Pharmacology, 15, 316-320. 